\title{
Strengthening of Reinforced Concrete Members using Post-Tension Cables: A Parametric Research
}

\author{
Hanadi Elkhansa, Oussama Baalbaki
}

\begin{abstract}
In building construction, post-tensioning allows longer clear spans, thinner slabs than the reinforced concrete beams. This paper presents a theoretical investigation on the behavior of existing reinforced concrete beams strengthened with post-tensioning cable(s) for increasing their load capacity. The proposed post-tensioning technique consists of stressing cable passing through a structural beam element starting from the top/bottom side and traversing the beam to the bottom/top side and then return back to the original side. A theoretical parametric study is conducted to study the effect of post-tensioning parameters on the internal stresses to optimize the design parameters. An excel spread sheet program was developed to calculate the internal straining actions at critical sections of the beam. A parametric study including the cable length, inclination angle of the cable and pre-stressing force magnitude was performed by using this program. This parametric study, led to well-defined guidelines for the proper use of the strengthening of beams by pre-stressing cables with adequate geometrical conditions of the cables.
\end{abstract}

Keywords-Post-tension, tendons, Concrete Repair, Strengthening

\section{INTRODUCTION}

External pre-stressing was first used in the late 1920's and has recently undergone a resurgence being used in bridges, both for new construction as well as strengthening of existing structures [1]. External pre-stressing is characterized by the following features:

- The pre-stressing tendons are placed on the outside of the physical cross section of the structure.

- The forces exerted by the pre-stressing tendons are only transferred to the structure at the anchorages and at deflectors

- No bond is present between the tendon and the structure, except at anchorage and deflector locations.

Strengthening of concrete structures was the primary goal of many researchers. Alkhrdaji and Thomas studied the effect of external post-tensioning on the stiffness of concrete structures [2], Krauser used external post-tensioning for repair, modify and strengthen of an existing structure [3], El-Hacha and Elbadry perform experiments on the use of carbon fiber reinforced polymer (CFRP) cables as external pre-stressing for strengthening of concrete flexural members [4]. Compared to internal bonded post-tensioning the external pre-stressing has the following distinct advantages: The application of external pre-stressing can be combined with a broad range of construction materials such as steel, timber, concrete, composite structures and plastic materials. This can considerably widen the scope of the post-tensioning applications $[5,6,7]$ Due to the location and accessibility of the tendons, monitoring and maintenance can be readily carried out compared to internal, bonded pre-stressing. Also, due to the absence of bond, it is possible to re-stress, de-stress and exchange any external pre-stressing cable, provided that the structural detailing allows for these actions $[8,9,10]$. Moreover, external pre-stressing improves the concrete placing due to the absence of tendons in the webs, and reduces the friction losses, because the unintentional angular changes, known as wobble, are practically eliminated. Furthermore the webs can be made thinner, resulting in an overall lighter structure. As an overall result, better concrete quality can be obtained leading to a more durable structure.

\section{THEORETICAL STUDY}

This study deals with the design and analysis of a section in reinforced concrete beams subjected to post-tensioning. For this, the computation of internal forces and internal shear and flexural stresses are presented in a spread sheet program based on the computation method developed for this purpose. Experimental flexural testing were conducted by researchers on rectangular beams with same reinforcement but they differ in the length of the cable and its angle of inclination ( $\alpha$ ). Five beams specimens of $1.5 \times 0.12 \times 0.24 \mathrm{~m}$ dimensions having rectangular sections were constructed and tested under two points load in this study. All beams are made with the same concrete mix and have same reinforcement but differ by one of the following parameters; bottom length of the cable $\left(l_{1}\right)$, its angle of inclination $(\alpha)$ and the value of the post-tensioning force $\left(\mathrm{P}_{1}\right)$, [12]. The experimental results showed that the strengthened beam with tensioned cables had better load capacity than regular Reinforced concrete beams without strengthening $[13,14]$.

\section{A. External Post Tension Technique}

With the proposed post-tensioning technique, the steel tendon is installed by traversing the concrete beam from top to bottom through the first inclined conduit along the bending moment zone and then from the bottom to top through the opposite conduit (Figure 1). The steel tendon is gripped at both ends, tensioned and anchored to stress the concrete. No bond is existent between the tendon and the structure, except at anchorage locations. The experimental study focused on the influence of posttensioned tendon on the beams flexural behavior and internal stresses. Theoretical analysis was performed to compare theoretical results to that obtained experimentally. 
The post-tensioning tendon is placed partially inside the cross section of the structure near the supports and externally closed to the bottom in the bending zone. The beam is stressed by the applied external forces resulting from anchors reactions transferred to the beam prior to applying any bending static load (2P). The inclined reaction forces $\left(\mathrm{P}_{1}\right)$ are decomposed into horizontal and vertical components at the anchors locations (Figure 1). For equilibrium of the system, a line uplift load at the contact of the tendon with the beam is developed to be in equilibrium with the vertical components $\left(\mathrm{P}_{1} \sin \alpha\right)$

\section{B. Analytical Analysis of Post-Tensioned R.C Beams}

Under this topic we design a post-tensioned reinforced concrete beam. Based on the rules and theories of the structural reinforced concrete design different equations and formulas are created to be used later in an excel spread sheet program to make a parametric study, also this program enables us to use more than one cable in the same position and many cables in different positions. Figure 2 shows the reinforcement details and beams cross sectional dimensions that will be used in the parametric study noting that the span length and the bottom cable length $\left(\mathrm{L}_{1} / 2\right)$ will vary depending on the case to be studied. Noting that concrete of $35 \mathrm{MPa}$ compressive strength and grade 60 rebars with $8 \mathrm{~mm}$ stirrups spaced by $120 \mathrm{~mm}$ were used in the calculation.

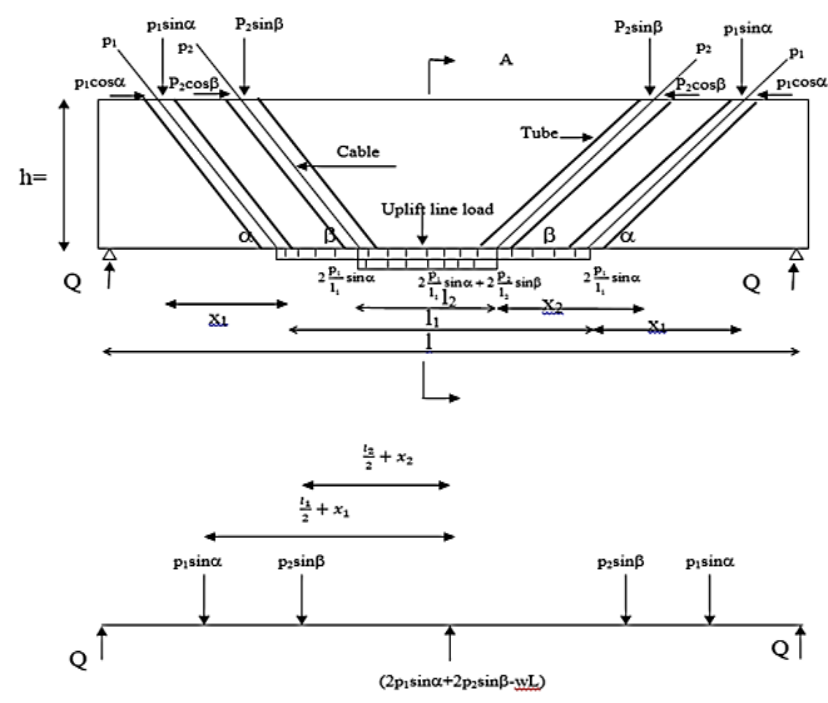

Figure. 1 Concrete Beam with two cables

Maximum moment at mid span:

$$
M_{\text {max }}=Q \frac{L}{2}-p_{1} \sin \alpha\left(x_{1}+\frac{l_{1}}{2}\right)-p_{2} \sin \beta\left(x_{2}+\frac{l_{2}}{2}\right)-\frac{W l^{2}}{8}+\frac{2 p_{1}}{l_{1}} \sin \alpha\left(\frac{l_{1}^{2}}{8}\right)+\frac{2 p_{2}}{l_{2}} \sin \beta\left(\frac{l_{2}^{2}}{8}\right)
$$

Normal Stresses in Concrete and Steel

Transformed section:

$$
A_{s}=\frac{\pi}{4} D_{b a r}^{2} \times \text { number }
$$

Assume all tensile forces are carried by the steel rods $n_{1}=\frac{E_{s}}{E_{c}}$

The transformed steel and cables area are: $n_{1} A_{s}$, $n_{2} A_{\text {cable }}$

$$
\text { Where } A_{\text {cab }}=4 \frac{\pi}{4} \varphi_{c}^{2}, \quad n_{2}=\frac{E_{\text {cables }}}{E_{c}} \text { and Neutral axis: } \Sigma M_{@ N . A}=0
$$

$$
\begin{gathered}
b x\left(\frac{x}{2}\right)-n_{1} A_{s}(d-x)-n_{2} A_{c a b}\left(h+\frac{\varphi_{c a b}}{2}-x\right)=0 \\
\Delta=\sqrt{b^{2}-4 a c}, a x^{2}+b x+c=0
\end{gathered}
$$

Moment of inertia:

$$
I=\frac{1}{3} b x^{3}+n_{1} A_{s}(d-x)^{2}+n_{2} A_{c a b}\left(h+\frac{\varphi}{2}-x\right)^{2}
$$

Maximum stress in concrete: (due to $\mathrm{M}$ )

$$
\sigma_{c}=\frac{M}{I} y_{t}<\sigma_{\text {all.c }}
$$

Stress in steel:

$$
\sigma_{s}=n_{1} \frac{M}{I} y_{b}<\sigma_{\text {all.s }}
$$

Stress in cables:

$$
\sigma_{c a b}=n_{2} \frac{M}{I} y_{b c}<\sigma_{a l l . c a b} \quad y_{b c}=h+\frac{\varphi_{c a b}}{2}-x
$$

Normal stress due to normal force in mid section (Fig.2): $p_{1} \cos \alpha+p_{2} \cos \beta$

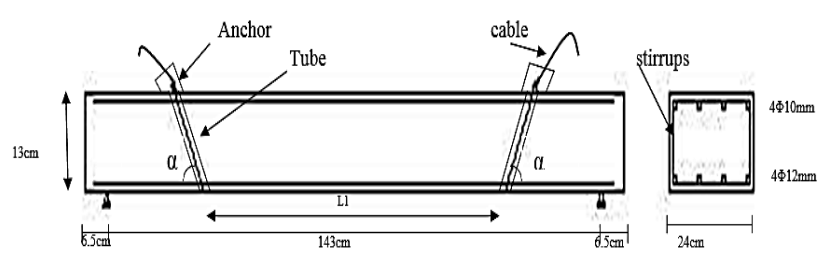

Figure. 2 Section of length $L_{1}$

$$
\begin{aligned}
& \text { In concrete: } \sigma_{c}=\frac{p_{1} \cos \alpha+p_{2} \cos \beta}{b h}+\frac{M}{I} y_{T} \\
& \text { In steel: } \sigma_{s}=n_{1} \frac{M}{I} y_{b}-\frac{p_{1} \cos \alpha+p_{2} \cos \beta}{b h} \\
& \text { In cables: } \sigma_{c a b}=n_{2} \frac{M}{I} y_{b c}-\frac{p_{1} \cos \alpha+p_{2} \cos \beta}{b h}
\end{aligned}
$$

\section{PARAMETRIC RESULT}

A parametric study was performed using an excel spread sheet program based on the computation method. The study covered the variation of the following parameters: the cable length, the angle of inclination $\alpha$ and the pre-stressing force in the cable.

\section{The Input Data of the Program}

Table 1 -Input data used for calculation

\begin{tabular}{cl} 
L & Span of the beam \\
\hline $\mathrm{b}$ & width of the beam \\
\hline $\mathrm{h}$ & thickness of the beam \\
\hline $\mathrm{wd}$ & dead load \\
\hline $\mathrm{wl}$ & live load \\
\hline $\mathrm{f}_{\mathrm{cu}}$ & ultimate compressive strength of the concrete \\
\hline $\mathrm{f}_{\mathrm{y}}$ & yield stress of the steel \\
\hline yc & material safety factor for concrete \\
\hline ys & material safety factor for steel
\end{tabular}




\begin{tabular}{cl} 
Rmax & value differ with the different types of steel \\
\hline $\begin{array}{c}\mathrm{D}: \text { no of } \\
\text { bars }\end{array}$ & diameter of the steel bars \\
\hline $\mathrm{E}_{\mathrm{s}}$ & $\begin{array}{l}\text { modulus of elasticity of the steel } \\
\text { reinforcement }\end{array}$ \\
\hline $\mathrm{E}_{\mathrm{c}}$ & modulus of elasticity of the concrete \\
\hline $\mathrm{y}$ & position of fibers from the neutral axis \\
\hline $\mathrm{P}_{1}$ & Pre-stressing force in the cable1 \\
\hline$\alpha$ & inclined angle of the cable 1 \\
\hline $\mathrm{l}_{1 / 2}$ & horizontal length of cable $1 / 2$ \\
\hline $\mathrm{E}_{\mathrm{cable}}$ & modulus of elasticity of the cable \\
\hline$\varphi_{\text {cable }}$ & diameter of the cable \\
\hline $\mathrm{N} \mathrm{cab}$ & Number of the cables \\
\hline $\mathrm{M}_{1}$ & bending moment at a certain section \\
\hline $\mathrm{d}_{\text {min }}$ & minimum diameter of the duct
\end{tabular}

\section{A. Effect of the Cable length on the Bending moment at mid span}

In this part, the angle of inclination $\alpha$ was kept constant, the pre-stressing force in the second cable was assumed to be 0 , and different values of the ratio $\mathrm{L}_{1} / \mathrm{L}$ were used.

- $\quad \mathrm{L}$ is constant and $\mathrm{L}_{1} / \mathrm{L}$ varies

The load $\mathrm{P}_{1}$ varies from 0 to 10 ton was used for different cases. The mid-span moment versus pre-stressing force curve is shown in Figure 3.

$\mathrm{L}=4 \mathrm{~m}, \alpha=45, \mathrm{P}_{2}=0$

Case 1: $\mathrm{L}_{1} / \mathrm{L}=0.2$, Case $2: \mathrm{L}_{1} / \mathrm{L}=0.4$, Case $3: \mathrm{L}_{1} / \mathrm{L}=0.6$, Case 4: $\mathrm{L}_{1} / \mathrm{L}=0.8$, Case $5: \mathrm{L}_{1} / \mathrm{L}=1$

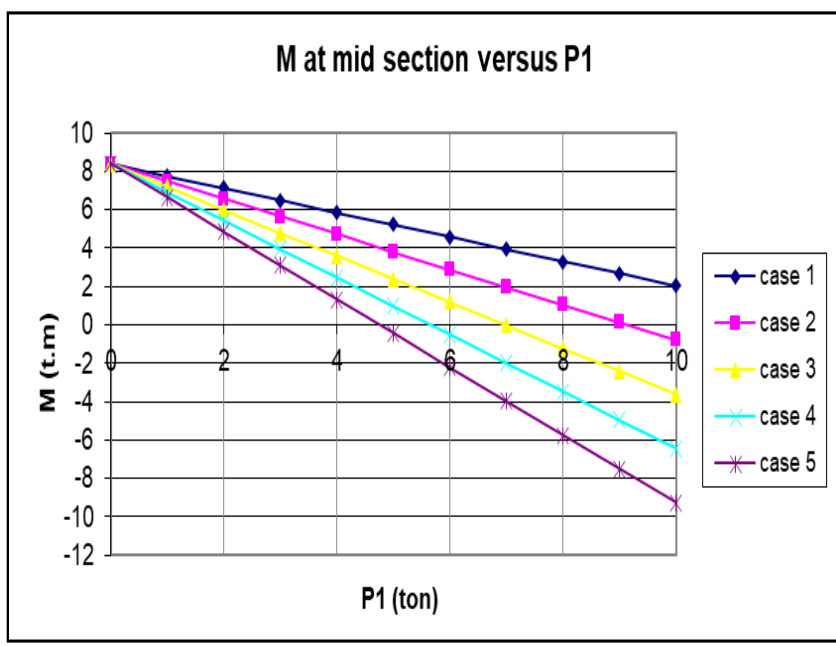

Figure 3 Moment versus Pre-stressing force

The load P1 varies from 0 to 10 ton for the cases $1 \& 2$, and from 0 to 20 ton for case 3 , then from 0 to 25 ton for the cases $4 \& 5$ as shown in Figure 4 .

$\mathrm{L}_{1} / \mathrm{L}=0.2 \alpha=45, \quad \mathrm{P}_{2}=0$

Case1: $\mathrm{L}=4 \mathrm{~m}$, Case 2: $\mathrm{L}=6 \mathrm{~m}$, Case 3: $\mathrm{L}=8 \mathrm{~m}$, Case4: $\mathrm{L}=$ 10, Case 5: $\mathrm{L}=12 \mathrm{~m}$.
- $\quad \mathrm{L}$ varies and $\mathrm{L}_{1} / \mathrm{L}$ is constant

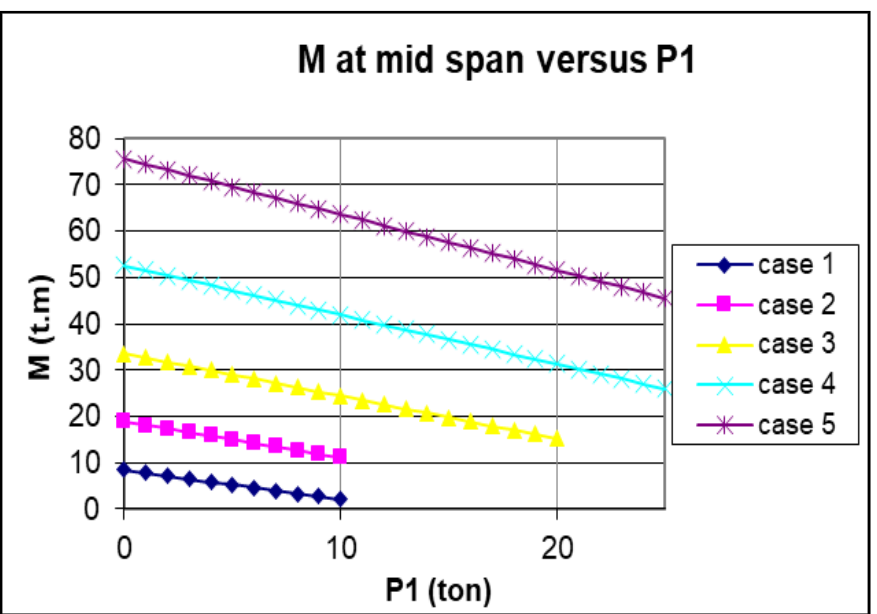

Figure 4 Moment versus Pre-stressing force

B. Effect of inclination angle $\alpha$ on the moment at the mid span

- $\quad \mathrm{L}_{1} / \mathrm{L}=0.6, \mathrm{~L}$ is constant $(\mathrm{L}=4 \mathrm{~m})$ and $\mathrm{P}_{1}$ varies:

Case $1 ; \mathrm{P}_{1}=2 \mathrm{t}$, Case $2 ; \mathrm{P}_{1}=4 \mathrm{t}$, Case $: 3 ; \mathrm{P}_{1}=6 \mathrm{t}$ Case $4 ; \mathrm{P}_{1}=8$, Case 5; $P_{1}=10 t, P_{1}=4 t, P_{1}=6 t, P_{1}=8 t, P_{1}=10 t$

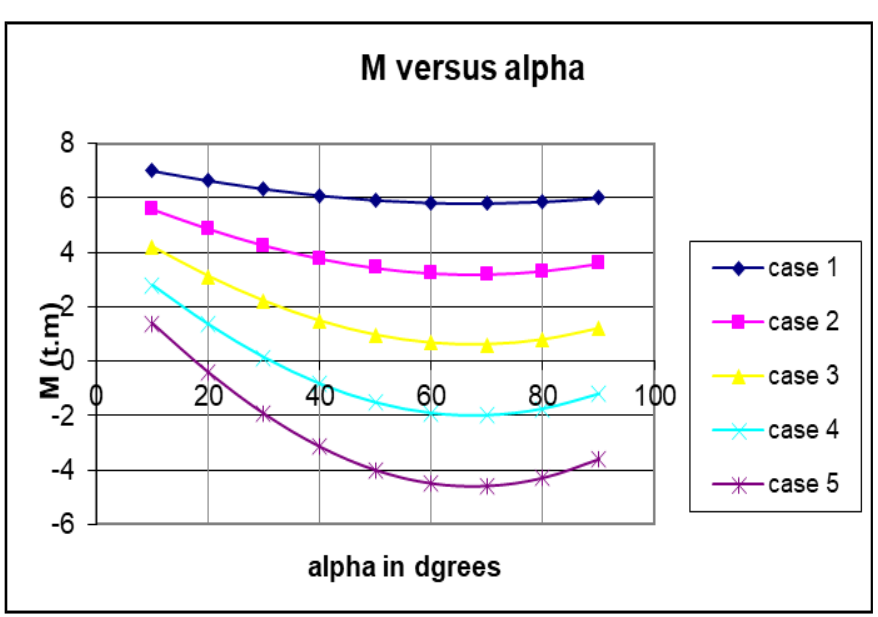

Figure 4 Moment versus inclination angle

$\mathrm{L}_{1} / \mathrm{L}=0.6, \mathrm{~L}$ is constant $(\mathrm{L}=6 \mathrm{~m})$ and $\mathrm{P}_{1}$ varies:

Case 1; $\mathrm{P}_{1}=2 \mathrm{t}$ Case 2; $\mathrm{P}_{1}=4 \mathrm{t}$, Case $3 ; \mathrm{P}_{1}=6 \mathrm{t}$ Case $4 ; \mathrm{P}_{1}=8 \mathrm{t}$, Case 5; $P_{1}=10 t$, (Figure 5)

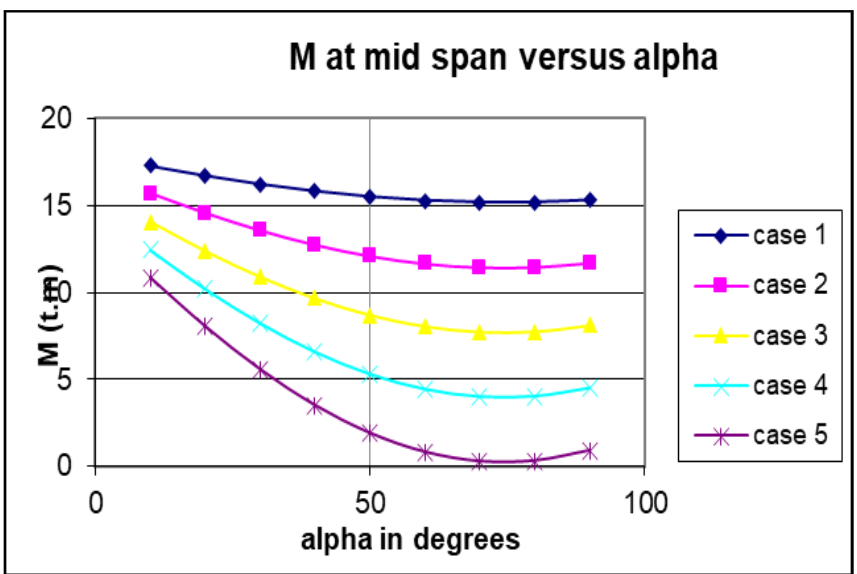

Figure 5 Moment versus inclination angle 
- $\quad \mathrm{L}_{1} / \mathrm{L}=0.6, \mathrm{~L}$ is constant $(\mathrm{L}=10 \mathrm{~m})$ and $\mathrm{P} 1$ varies:

Case $1 ; \mathrm{P}_{1}=5$ t Case 2; $\mathrm{P}_{1}=10 \mathrm{t}$, Case $3 ; \mathrm{P}_{1}=15 \mathrm{t}$ Case 4; $P_{1}=20$, Case 5; $P_{1}=20 t$, (Figure 6)

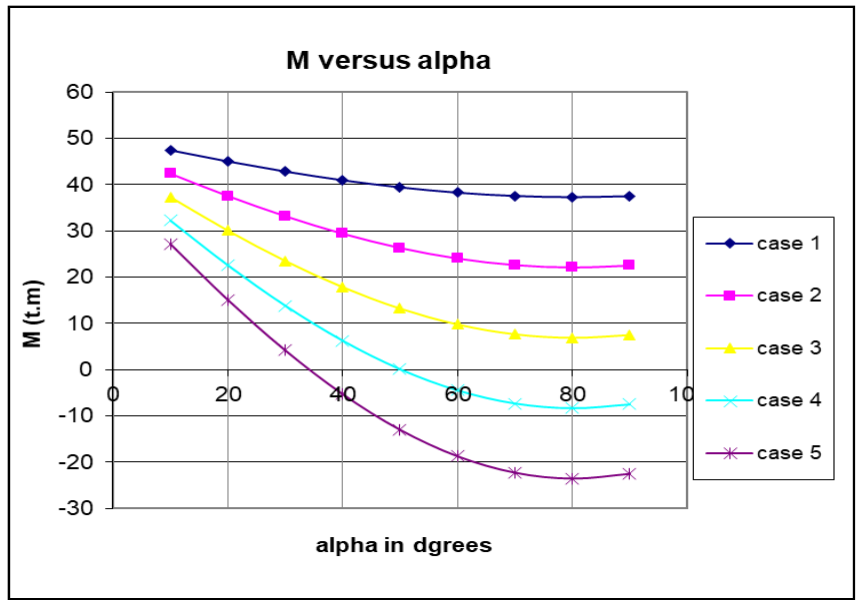

Figure 6 Moment versus inclination angle

\section{Effect of the ratios P2/P1 on the moment at the mid span}

(case of 2 cables), $L_{2} / L_{1}$ and $P_{1}+P_{2}=$ constant, $P_{2} / P_{1}$ is variable), $L_{1} / L=0.6 \& P_{1}+P_{2}=6 t, \alpha=\beta=60^{\circ}$, (Figure 7,8) - $\quad P_{2} / P_{1}=0.5$

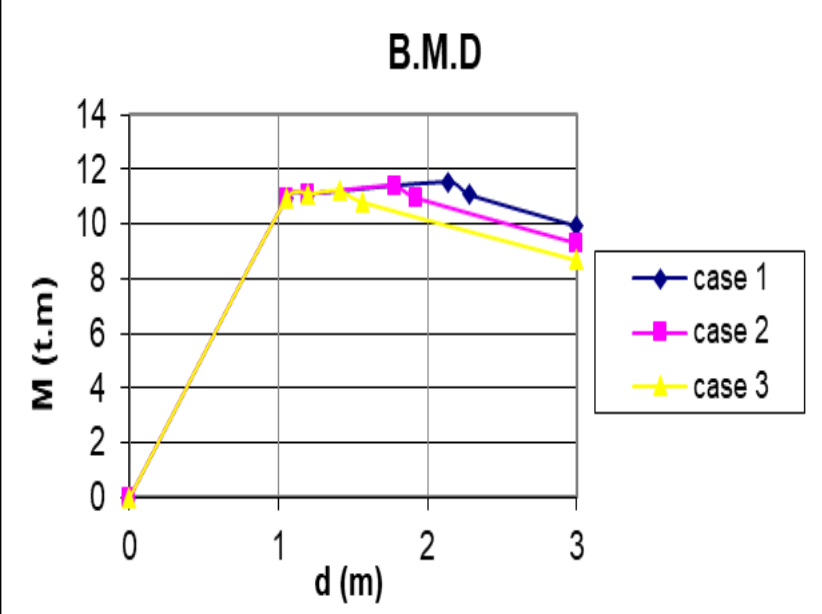

Figure 7 Reduction in Moment at mid-section

- $\quad P_{2} / P_{1}=1.5$

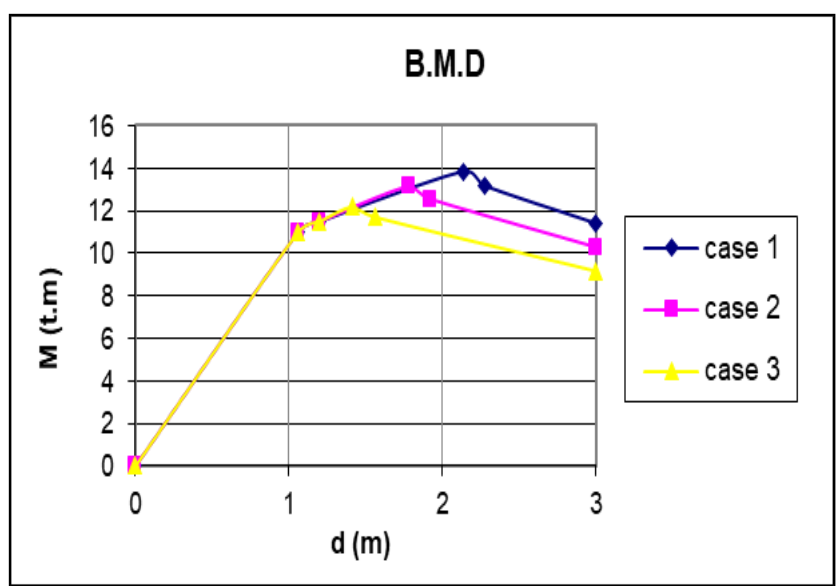

Figure 8 Reduction in Moment at mid-section

\section{CONCLUSION}

The major results obtained from this parametric study are summarized as follows:

1. The study developed new simplified and accurate computation method allowing to enhance the flexural strength.

2. The study led to well-defined guidelines for the proper use of the strengthening of beams by pre-stressing cables with adequate length and angle.

3. All the beams with post-tensioned cable admit a better performance in terms of ductility and capacity when the ratio $L_{1} / L>0.6$, and the angle of inclination $\alpha$ satisfies the following $45^{\circ} \leq \alpha \leq 65^{\circ}$.

For the same length of the beam L, and same $\alpha$, we notice that as $\mathrm{L}_{1} / \mathrm{L}$ increases, the required jacking force in the cable $\left(\mathrm{P}_{1}\right)$ will decrease to reduce the moment at the mid-span.

\section{REFERENCES}

1. A.F.Daly and W. Witarnawan, "Strengthening of bridges using external post-tensioning”, Road Research Development Project, Published Paper PA 11, East 97, Seoul, Korea, 29-31 Octobe 1997.

2. Tarek Alkhrdaji, and Jay Thomas, "Structural Strengthening Using External Post-Tensioning Systems" 2018.

3. Larry Krauser, "Repairs, Modifications, and Strengthening with Post-tensioning” July 2006.

4. Refaat El-Hacha and Mamdouh El-Badry, "Strengthening Concrete Beams with Externally Pre-stressed Carbon Fibe Composite Cables: Experimental Investigation” December 2006.

5. Edward G.Nawy, "Pre-stressed concrete (A fundamental approach)", fifth edition.

6. R.C. Hibbler, "Structural Analysis", sixth edition.

7. Ferdinand P.Beer, E.Russel Johnston and John T.Dewolf, "Mechanics of materials".

8. United States Department of Transportation-Federal Highway Administration-Infrastructure, "Post-tensioning Tendon, Installation and Grouting Manual".

9. American Concrete Institute, "Building Code Requirements for Reinforced Concrete (ACI 318-99) and commentary (ACI 318R-99)" ACI 318-99, Farmington Hills, Michigan.

10. Antoine E. Naaman, Prestressed Concrete Analysis and Design Fundamentals. Second Edition, Ann Arbor, Michigan 48109-2125, USA (2004).

11. Keven Q. Walsh and Yehya C. Kumara, " Behavior of Un-bonded Post-Tensioning anchoring Systems Under Monotonic Tensile Loading”, PTI Journal, Winter 2010.

12. Oussama M, Baalbaki, "A Practical Strengthening Scheme of Reinforced Concrete Beams Using Post-Tensiong Tendons", European Journal of Scientific Research,2010 ISSN 1450-216X

13. Mona Sabra, Oussama Baalbaki, Yehia Temsah, Zaher Abou Saleh, Repair of Pre-stressed Concrete Beams using Coupler and Pre-stressed Strands, International Conference on Engineering and Architecture, Nov 2018, Alanya, Turkey

14. M. Y. Sabra, Y. A. Temsah, O. M. Baalbaki, Z. Abou. Saleh, International Journal of Civil Engineering and Technology (IJCIET), Volume 9, Issue 10, October 2018, pp. 427-440, Article ID: IJCIET $09 \quad 10 \_044$

15. http://www.iaeme.com/ijciet/issues, ISSN Print: 0976-6308 and ISSN Online: 0976-6316 


\section{LIST OF SYMBOLS}

$\mathrm{A}_{\mathrm{s}} \quad$ area of the steel reinforcement

$\mathrm{n}_{1} \quad$ ratio $=\mathrm{E}_{\mathrm{s}} / \mathrm{E}_{\mathrm{c}}$

discriminant to find the position of the neutral

$\Delta \quad$ axis

$\mathrm{x} \quad$ the neutral axis depth

I moment of inertia of the transformed section position of the top fibers of the section from $\mathrm{y}_{\mathrm{t}} \quad$ the neutral axis position of the bottom fibers of the section

$\mathrm{y}_{\mathrm{b}} \quad$ from the neutral axis allowable compressive strength of the $\sigma_{\mathrm{c}, \text { all }} \quad$ concrete

$\sigma_{\mathrm{s}, \text { all }} \quad$ allowable tensile stress of the steel

$\sigma_{c} \quad$ compressive strength of the concrete

$\sigma_{\mathrm{s}} \quad$ tensile stress of the steel

A area of the concrete section

$y$ position of fibers from the neutral axis

c half of the concrete thickness

$\mathrm{P}_{1} \quad$ Pre-stressing force in the cable1

$\alpha \quad$ inclined angle of the cable 1

horizontal projection of the inclined part in

$\mathrm{x}_{1} \quad$ cable 1

$\mathrm{L}_{1} \quad$ horizontal length of cable1

$\mathrm{P}_{2} \quad$ Pre-stressing force in the cable2

$\beta \quad$ inclined angle of the cable 2 